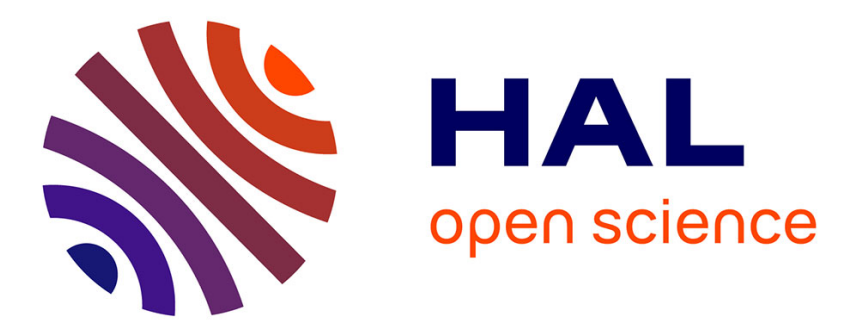

\title{
Mobile Crowd Sensing of Water Level to Improve Flood Forecasting in Small Drainage Areas
}

Simon Burkard, Frank Fuchs-Kittowski, Anna Bhroithe

\section{To cite this version:}

Simon Burkard, Frank Fuchs-Kittowski, Anna Bhroithe. Mobile Crowd Sensing of Water Level to Improve Flood Forecasting in Small Drainage Areas. 12th International Symposium on Environmental Software Systems (ISESS), May 2017, Zadar, Croatia. pp.124-138, 10.1007/978-3-319-89935-0_11. hal-01852636

\section{HAL Id: hal-01852636 \\ https://hal.inria.fr/hal-01852636}

Submitted on 2 Aug 2018

HAL is a multi-disciplinary open access archive for the deposit and dissemination of scientific research documents, whether they are published or not. The documents may come from teaching and research institutions in France or abroad, or from public or private research centers.
L'archive ouverte pluridisciplinaire HAL, est destinée au dépôt et à la diffusion de documents scientifiques de niveau recherche, publiés ou non, émanant des établissements d'enseignement et de recherche français ou étrangers, des laboratoires publics ou privés. 


\title{
Mobile crowd sensing of water level to improve flood forecasting in small drainage areas
}

\author{
Simon Burkard, Frank Fuchs-Kittowski, Anna O'Faolain de Bhroithe \\ HTW Berlin, Berlin, Germany \\ \{s.burkard, frank.fuchs-kittowski, Anna.OFaolaindeBhroithe@htw-berlin.de\}@htw- \\ berlin.de
}

\begin{abstract}
Flood forecasting is particularly difficult and uncertain for small drainage basins. One reason for this is due to inadequate temporal and spatial hydrological input variables for model-based flood predictions. Incorporating additional information collected by volunteers with the help of their smartphones can improve flood forecasting systems. Data collected in this way is often referred to VGI data (Volunteered Geographic Information data). This paper discusses how this information can be incorporated into a flood forecasting system to support flood management in small drainage basins on the basis of mobile VGI data. It therefore outlines the main functional components involved in such a VGI-based flood forecasting platform while presenting the component for mobile data acquisition (mobile sensing) in more detail. In this context, relevant measurement variables are first introduced and then suitable methods for recording these data with mobile devices are described. The focus of the paper lies on discussing various methods for measuring the water level using inbuilt smartphone sensors. For this purpose, three different image-based methods for measuring the water level at the banks of small rivers using a mobile device and the inbuilt orientation and camera sensors are explained in detail. It is shown that performing the measurements with the user's help via appropriate user interaction and utilising known structures at the measuring points results in a rather robust image-based measurement of the water level. A preliminary evaluation of the methods under ideal conditions found that the developed measurement techniques can achieve both an accuracy and precision of less than $1 \mathrm{~cm}$.
\end{abstract}

Keywords: Flood forecasting, Crowd sourcing, Mobile sensing, VGI, Water level

\section{Improvement of flood forecasting in small drainage basins through citizen participation in data collection}

Floods are one of the natural hazards that directly threaten the civilian population, regularly causing extensive material damage and costing many lives. Damage as a result of flooding has increased considerably in recent decades [1]. There is a very high probability that this trend will continue and the intensity of floods will continue to increase [2]. This is due in particular to the increase in short-term, local flood events. In order to reduce the harmful impact of floods and to be able to take targeted protective

adfa, p. 1, 2011.

(C) Springer-Verlag Berlin Heidelberg 2011 
measures, disaster relief forces and the affected population must be informed early and reliably of imminent threats through forecasting and early warning systems [3].

Hydrological and hydraulic forecasting models are used as the basis for decisionmaking for disaster relief measures. Model-based flood predictions are, however, often uncertain and error-prone. The reasons for this include uncertainties on the model and precipitation forecasts, as well as inadequate temporal and spatial hydrological input variables. Predictions are especially difficult for small bodies of water since very fast responses of the basin often occur, leaving very little warning time. There is often insufficient official data for these exceptional situations. However, extra information, such as additional water level measurements along a river, can be used to extend these important data sets and update the forecast models in order to reduce the uncertainties on the forecast [4].

Such additional hydrological data can also be voluntarily recorded and provided by citizens using the inbuilt sensors in their own devices (e.g., smartphones, tablets, etc.) via mobile crowdsourcing and sensing [5]. Location-specific data collected in this way is often referred to VGI data (Volunteered Geographic Information data) [6-8]. By incorporating VGI data, the amount of spatial and temporal input information for the prediction models can be increased, reducing uncertainties and therefore improving the predictions of flood forecasting systems. In addition, involving the population in the process raises awareness of flood hazards and citizens can actively contribute to improving flood forecasts and reducing flood damage [9].

In this article, methods for measuring the water level using smartphone sensors (mobile sensing) are presented. It is also discussed how this information can be incorporated into a flood forecasting system to support flood management in small drainage basins on the basis of mobile VGI data. The article is structured as follows: after an overview of the current status of the science and technology (Section 2), the conceptual architecture of such a VGI-based flood management platform is outlined and the functional components involved are described (Section 3). The component for mobile data acquisition (mobile sensing) is then presented in more detail. For this purpose, relevant measurement variables are first introduced and then suitable methods for recording these data with mobile devices are described (Section 4). Various methods for measuring the water level using inbuilt smartphone sensors are explained in detail and evaluated (Section 5). A final summary provides on outlook on future developments within the framework of the presented platform (Section 6).

\section{Current status of research and technology}

\subsection{Mobile crowdsourcing and VGI in disaster management}

Mobile crowdsourcing refers to the use of mobile devices to collect data as well as to coordinate volunteers involved in the data collection. The core concept is that ordinary citizens collect and share information about themselves or the surrounding environment using their own mobile devices. The participants contribute the data voluntarily, for their own benefit or for the benefit of a community. No task-specific special hardware is used, only normal mobile devices available on the mass market such as smartphones 
and tablets [5]. The required data is recorded using the built-in sensors in the mobile devices (mobile sensing). Volunteers can be proactively prompted to collect data, and their tasks can be coordinated (mobile tasking $[10,11]$ ). The recorded data are known as VGI data [6] - usually geospatial measurements that are also often time-referenced.

Closely related to the notion of mobile crowdsourcing are concepts such as VGI [68], Public Participatory Geographic Information Systems (PPGIS [12]), and Participatory Sensing (PS [13]). Common to all concepts is the voluntary and collaborative nature of the data collection and data sharing process.

There are already many different crowdsourcing applications, especially in nature conservation, environmental protection, and disaster management [5]. In disaster management, mobile crowdsourcing can be used to great effect both during and after a catastrophe $[11,14]$. For example, in a catastrophe, residents and rescue and emergency personnel can gather information about the current situation in the affected area so that aid and rescue workers can target the most critical zones. After a natural disaster (such as a flood, storm, or heavy rain), finding, documenting, and evaluating damage (such as fallen trees, flooded roads and paths, fallen power masts) is an important task that allows the limited resources to be deployed more quickly and accurately to begin cleanup and repairs. It also allows assessments of the total damage to be up-to-date and comprehensive [15].

Mobile crowdsourcing applications have already been successfully used in disaster situations, but the accuracy and quality of the information has been of minor importance. VGI data have been used, for example, during floods [16-18], wildfires [19], earthquakes [20], and even severe storms [21]. In the system presented in Section 3, VGI data is utilised, among other things, to update and validate forecast models. Therefore, there is a stronger focus on the accuracy and quality of the data recorded using mobile data collection methods.

\subsection{Flow measurement and mobile sensing for flood forecasting}

Hydrological data which can be used to measure the water flow are of particular importance for flood prediction. Flow measurements in hydrometry are mostly indirect and rely on known flow cross sections and measurements of the flow speed and the water level [22]. Approaches to automatic flow measurement from images already exist. These are based on remote sensing methods which can be used to estimate the level of a body of water using aerial photographs [23], for example. Another example is the use of permanently installed cameras for the image-based measurement of the water level using markers or staff gauges [24-27]. The idea to have passers-by read off the water level at staff gauges was also successfully tested. The reading was sent via SMS [28] or an app [9] to a data server for evaluation.

The collection of data by mobile users does not necessarily involve manual data input, e.g., in a form, but can be automated by using the sensors already present in mobile devices. The term "mobile sensing" has been established to describe the acquisition and generation of data using the sensors installed in or connected to peoples' own mobile devices [5]. A mobile sensing application specifically for automatic image-based gauge monitoring has been developed by [29]. However, special staff gauges are required for 
robust measurements, as well as certain other factors such as sufficient brightness and a small distance between the camera and the indicator.

The sensor-based determination of water level lines by mobile devices can be facilitated by the knowledge of the device's exact position in 3D space. Therefore, research in the areas of mobile augmented reality and mobile 3D tracking for position determination is also of interest. These areas of research are still relatively new, but there are already several approaches and technologies for the image-based estimation of a device's own position in 3D space that are more accurate than the localisation provided by GPS signals [30]. There are currently no known existing applications that use such technologies for VGI-based determination of hydrological data.

While there are many mobile applications for information about water levels (e.g., Pegel $^{1}$, Pegelstand ${ }^{2}$, Pegel-Online ${ }^{3}$, Pegelstände ${ }^{4}$, Meine Pegel ${ }^{5}$ ), very few mobile apps exist that allow users to measure the water level. For example, the MAGUN research project has developed mobile applications for the acquisition of current water levels and also historical high water marks [31], but these are not in widespread use. The goal of the WeSenseIt project is to design and test a complete platform for citizen-based documentation and monitoring of water levels and floods [32-33]. Smartphones as well as various other cost-effective sensors are used for the measurement of hydrological data such as water levels and flow speeds in the project. Information on the robustness and quality of the measured data is, however, not documented. The measured data is also not intended to be directly embedded in a prediction model, i.e., the integration of the data (or the entire process) into a concrete operational scenario - such as flood management - is missing.

\section{Conceptual architecture of a VGI-based prediction system}

In this section, the conceptual architecture of VGI-based flood forecasting system is proposed and described. This architecture is based on concepts of generic architectures for crowdsourcing [34] and crowdtasking applications [10], and has been specifically adapted for VGI-based flood forecasting systems. The functional components are illustrated in Figure 1. In addition to an adapted classical flood forecasting system and central flood management software, the platform includes components for mobile tasking and mobile sensing.

\subsection{Mobile tasking and mobile smartphone application}

Volunteers should have the possibility to independently decide if, and in what form, they wish to record and provide measurements. With the help of smartphone notifications, volunteers can be additionally instructed to record and send data at certain times

\footnotetext{
${ }^{1}$ https://play.google.com/store/apps/details?id=de.posts.Pegel

${ }^{2}$ https://play.google.com/store/apps/details?id=info.pegelstand.pegelstandnoebasic

${ }^{3}$ https://play.google.com/store/apps/details?id=org.cirrus.mobi.pegel

${ }^{4}$ https://play.google.com/store/apps/details?id=com.lifestream_creations.pegelmelder

${ }^{5}$ https://play.google.com/store/apps/details?id=de.hochwasserzentralen.app\&hl=de
} 
(mobile tasking). These notifications can be created and sent manually, but can also be sent automatically when coupled with an early warning system. For example, volunteers can be automatically notified and instructed to collect data when heavy rain and potential floods are forecast.

Hydrological data are collected via a smartphone application (mobile sensing) in the drainage basin(s) indicated in the flood forecast. The measured data can then be sent over the mobile network or a WLAN connection to a central server for further processing.

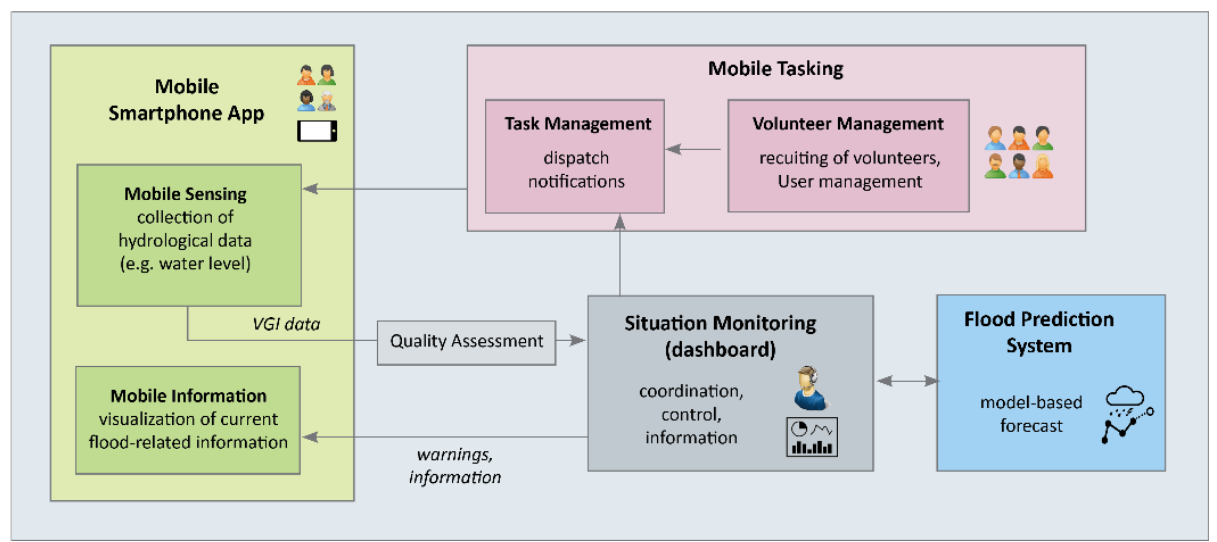

Fig. 1. Conceptual architecture of a VGI-based flood forecasting platform

Ideally, the measurements should be made using the integrated sensors in mobile devices. These sensors include GPS sensors for rough positioning (accuracy up to 5 - 10 meters) and tilt sensors (compass, accelerometers, magnetometers) for determining the viewing direction of the device as well as the integrated camera used to record images. The use of these sensors, in particular for the measurement of water levels, is explained in more detail in Sections 4 and 5.

In addition to the ability to record and send user-generated data, the mobile application is also intended to provide users with relevant information about floods. With the help of flood risk maps and the representation of current water levels in the area, the user is kept informed about flood risks and the current flood situation.

\subsection{Model-assisted flood forecasting system}

A problem of user-generated data is that the quality and accuracy of the data can vary considerably. Before the measured hydrological data are finally made available to the forecast system as input variables, an automatic quality and plausibility check of the incoming data is necessary. By means of a spatial and temporal comparison of the VGI data sets, erroneous input data (outliers) can be identified and eliminated. Based on a classical model-assisted prediction system, the system can subsequently supplement or validate the underlying model using the available VGI data in order to provide an improved flood forecast. 


\subsection{Situation monitoring}

A web-based user interface (dashboard) is used for situation monitoring. Incoming VGI data and flood forecasts are processed and appropriately visualised to enable an effective assessment of the flood situation. Besides the map-based representations and listings of current and historical VGI measurements and photographs, the hydrographs for the floods as well as official meteorological data such as radar images for precipitation forecasting are also displayed.

\section{Mobile sensing - relevant variables and methods}

With the help of the mobile smartphone application, certain parameters can be measured and made available by the volunteers. Relevant parameters are shown in Figure 2. The selection of parameters that should ultimately be measured results from a consideration of the additional gain provided for the hydrological prediction model versus the technical feasibility of robust mobile measurement methods for these parameters.

The water level and the flow speed of the water at defined measuring points are decisive inputs for the hydrological forecasting system as both parameters are relevant for the direct measurement of the flow rate. However, a meaningful measurement of the flow rate from smartphone measurements alone is very difficult. A rough estimate from the mobile user of the flow rate of the body of water is possible (e.g., "flow is very fast" or "flow is very slow") but an indication of the speed without a physical unit (e.g., meters per second) is not a useful input variable for the prediction system. An image-based estimate of the flow using a smartphone camera would be conceivable [35]. However, such an approach is quite complex and requires a fixed position from which to record as well as ideal external recording conditions (e.g., ideal lighting conditions). Additionally, it is only possible to roughly estimate the flow speed at the water's surface, but not the speed of currents below the surface. For the mobile measurement of the water level, however, there are several approaches. These techniques are presented in detail in Section 5. 


\begin{tabular}{|c|c|c|c|}
\hline & Measurement Parameters & Manual Measurement & Automatic Measurement \\
\hline$\approx$ & Water Level & $\begin{array}{l}\text { Estimate / } \\
\text { reading of staff gauge }\end{array}$ & $\begin{array}{l}\text { IMU-based or image-based detection } \\
\text { (with/without user interaction) }\end{array}$ \\
\hline \multirow[t]{2}{*}{$\approx$} & Flow Velocity & $\begin{array}{l}\text { Rough estimate } \\
\text { ("slow", „fast) }\end{array}$ & $\begin{array}{l}\text { Image-based estimation of } \\
\text { flow velocity }\end{array}$ \\
\hline & Precipitation Intensity & $\begin{array}{c}\text { Rough estimate } \\
\text { („,no rain", „little rain“, } \\
\text { „heavy rain") }\end{array}$ & Image-based estimation \\
\hline$\downarrow$ & Depth of Snow & Rough estimate & \\
\hline & $\begin{array}{l}\text { Photos \& Videos } \\
\text { (water levels, flood } \\
\text { damages, etc.) }\end{array}$ & \multicolumn{2}{|c|}{$\begin{array}{l}\text { Capturing of images \& videos via smartphone camera; } \\
\text { location determination via GPS sensor }\end{array}$} \\
\hline
\end{tabular}

Fig. 2. Relevant parameters and possible measurement methods

Other relevant input parameters for the model are the current precipitation intensity and the depth of snow. However, robust automatic measurement methods using smartphones are difficult to implement for these parameters. Although an image-based estimate of the current rain intensity is possible [36], the result is often erroneous. Instead, a manual estimate of the intensity of precipitation can be provided directly by the volunteer. This rough estimate of the intensity ("no rain”, "light rain”, "heavy rain"), combined with the location of the user as determined by the GPS signal, is helpful for improving the localisation of strong precipitation cells.

The depth of snow can also be estimated by the volunteer. A rough knowledge of the snow conditions with high spatial resolution facilitates an estimate of the volume of water contained within the snow cover in the drainage basin. This estimate can be of great benefit as an input parameter for the prediction model.

In addition to these quantitatively measurable values, photographs and short video clips taken with the smartphone camera can be included. These recordings can be displayed on the dashboard map and aid the relief forces in assessing and documenting the flood situation in the field. Measured water levels can be augmented with additional images. This function can also be used to locate floods and flood damage. Volunteers can, for example, monitor critical locations in case of a flood threat to see if a flood has actually occurred and if so, take pictures to document and share its extent.

\section{$5 \quad$ Methods for water level measurement}

The main focus of the development of the mobile sensing component is the implementation of suitable methods for measuring the water level with a smartphone. Measurements of the water level are not taken at arbitrary locations, but at fixed measuring points (e.g., bridges). There are several possible methods available to measure the water level with a smartphone, see Figure 3. The functionality and suitability of these methods 
will be described in more detail in the following section. The focus of the current discussion is the presentation and evaluation of the methods for semi-automatic imagebased measurements.

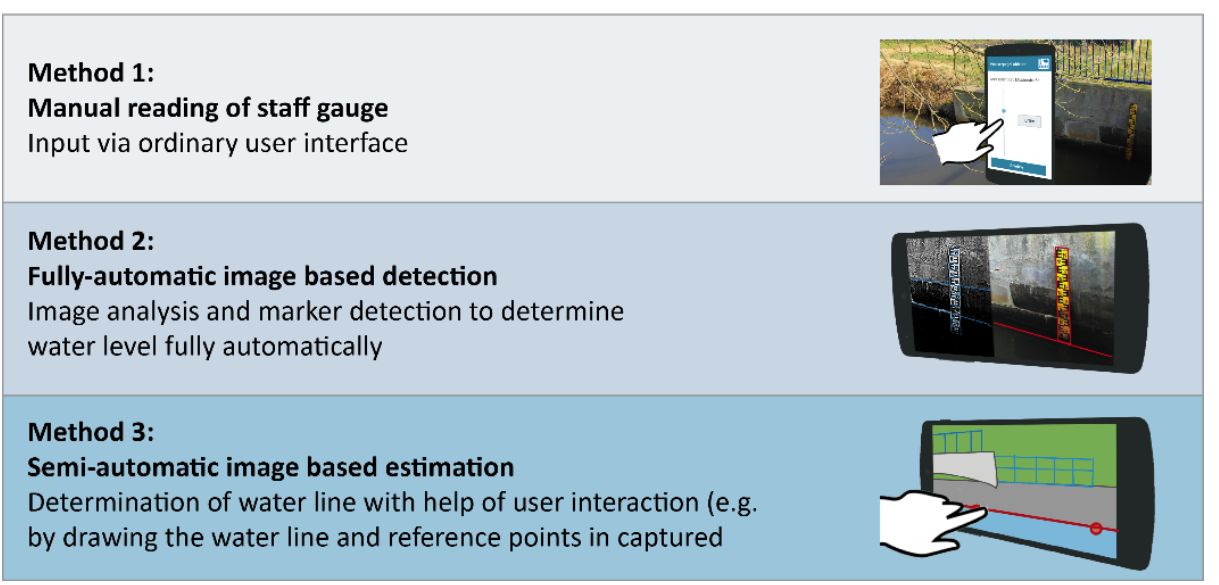

Fig. 3. Options for mobile water level measurement

\subsection{Manual reading of staff gauges}

In the simplest case, the water level can be measured by simply reading it from an existing calibrated staff gauge and entering the value into the smartphone application via a classic interface (e.g., slider or text input field). This method is quite robust. It is independent of the smartphone sensor and is also possible under unfavourable lighting and weather conditions. However, visible and accessible staff gauges that have been calibrated and installed at the measuring points are a prerequisite for this method.

\subsection{Fully automatic image-based water level measurement}

Another option is a fully automatic image-based measurement of the water level. The general idea is that, after taking a photograph from a more variable position, an image analysis algorithm automatically determines the water level from the picture without further input from the user. A prerequisite for this method is the presence of an appropriate marker. This can be an easily-visible staff gauge or other artificial marker. The area of the marker still visible above the water line can be determined by means of classical image or text recognition algorithms in order to determine the water line and thus the water level. As the appearance of the markers is known in advance, the recognition algorithms can be specially trained and adapted for this particular application using test images.

Under ideal conditions, such a fully automatic procedure facilitates high-accuracy measurements, but the method is not always sufficiently robust and is often error-prone. The marker is often not sufficiently visible or the water line not sufficiently pronounced due to general light conditions (e.g., shadows or darkness) or close-by structures (e.g., 
walls with uneven surfaces). Other structures are often more prominent in the photograph and interfere with the algorithms' recognition of the marker or water line.

\subsection{Semi-automatic image-based measurement}

Performing the measurements with the user's help via appropriate user interaction (e.g., drawing reference points on the image) and utilising known structures at the measuring points (e.g., a building on the river bank) results in a rather robust image-based measurement of the water level. As the measurements are made at predefined points and the flow cross section at these points must be known in advance of the flow calculation, it can be assumed that the dimensions of surrounding structures at these location are also known, e.g., the height and width of a bridge railing or the height of a wall beside the river relative to the riverbed (the zero-point of the gauge). This knowledge can be used in the development of the measurement method. In the following subsections, three different methods to measure the water level using the camera and orientation sensors of a smartphone, assuming the parameters mentioned above are known, are presented. The three variants are roughly sketched in Figure 4.

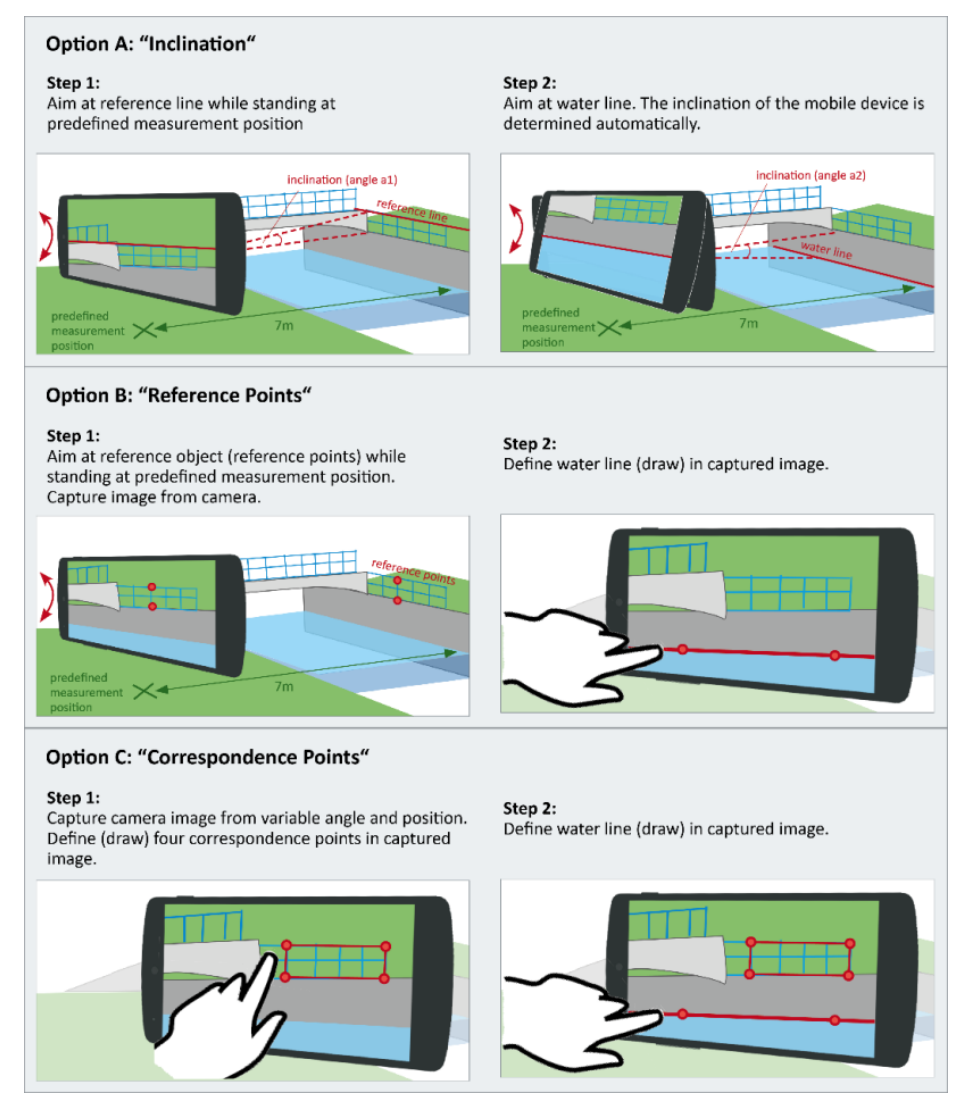

Fig. 4. Methods for semi-automatic image-based water level measurement 
Variant A - Inclination. The general idea of this variant is that the inclination of the device with respect to a predefined reference line on the opposite bank of the river and the current water level is measured with the aid of the smartphone's rotational sensors (accelerometer and gyroscope). If the measurement is always preformed at a fixed measuring point, the current water level can be determined. A requirement for the procedure is that the reference line must be parallel to the horizontal water line and in a plane orthogonal to the water surface. Quay walls or boundary walls or railings are usually suitable for this purpose. The measuring point should be parallel to the reference line on the opposite side of the river. A horizontal line is overlaid in real time on the camera image. The user first aligns this displayed line with actual reference line by rotating the phone and confirming once both lines coincide. In the second step, the user performs an analogous process, this time aligning the displayed line with the water line. If the height of the reference line relative to the river bed (the zero level point) is known along with the orthogonal distance between the measuring point and the reference line, the water level can be calculated using trigonometry.

Variant B - Reference points. This variant also assumes that the measurement is made from a fixed point. Additionally - analogous to variant A - a reference object or at least two reference points with a known position relative to the measuring point must be present on the opposite side of the river.

The position (3D coordinates) of the reference points are defined with respect to a predefined position of the smartphone camera (camera coordinate system) at the measuring point. The camera projection matrix (an intrinsic parameter of the camera) is used to calculate a projection of the points onto the camera image. This projection is displayed over the camera image. In calculating the projection, no rotation is taken into account, i.e., the identity matrix is defined as a fixed orientation. The orientation sensors are not used in this variant.

The user rotates the smartphone in the first step until the projected reference points are directly aligned with the actual reference points in the image. In this way, the rotation matrix of the device is forced fixed to be the identity matrix (i.e., zero rotation). From this camera position, the user then takes a high-resolution photograph. In the second step, the user indicates the water line in the photograph. This can be done, for example, by moving two points around on the picture, which when taken together, define the water line. The water level can then be derived in a simple manner given a knowledge of the position of the measuring point with respect to the reference points and the river bed (zero level point) and with the requirement that the water line and the reference points lie in the same plane.

Variant C - Correspondence points. This last variant is based on the general idea that the measuring position can be determined if the user draws at least four points on the image that correspond to known reference points. In contrast to the former two variants, no fixed measuring position is required for this method. The user can take a photograph from any position provided that the defined reference points are located within the field of view of the camera. The chosen reference points must lie in the same plane as the water line on the opposite side of the river bank, as in the previous variants. Furthermore, it is assumed that the distances between the each of the reference points and the zero level point (river bed) are known. Following a manual selection by the 
user of the reference points in the photograph, a homographic relationship can be determined between the camera image plane P1 and the plane P2 on the opposite side of the river in which the reference points lie. In the second step, the water line is additionally drawn on the image by the user, that is to say in the plane P1, and this line can be projected onto P2 using the known homography. In this way, the water level can be directly determined in the coordinate system of P2.

\subsection{Evaluation}

The three variants for measuring the water level were implemented in a demo application for the Android platform. With this prototype, it was possible to test the accuracy and precision achieved by each method when measurements were taken under ideal conditions.

To perform the measurements, reference lines or a reference object (dimensions: $150 \mathrm{~cm} \times 55 \mathrm{~cm}$ ) as well as a fictitious water level were defined on a vertical wall in order to simulate an ideal measuring site on a small river. The imaginary water level was drawn at $95 \mathrm{~cm}$ above the ground (defined as the zero point). The water level was measured with each of the three methods using a Galaxy S4 (GT-I9515) as a test mobile device. For each method, the measurement was repeated 20 times. For variants A and $\mathrm{B}$, which both require a fixed measuring point, the measurements were performed at a distance of $300 \mathrm{~cm}$ from the reference object. For variant B, a camera height of $150 \mathrm{~cm}$ was also defined. For variant $\mathrm{C}$, the distance between the measuring point and the reference object varied from about $200 \mathrm{~cm}$ to $400 \mathrm{~cm}$, and the viewing angle varied up to \pm 45 degrees. The results of the test measurements are shown in Figure 5 .

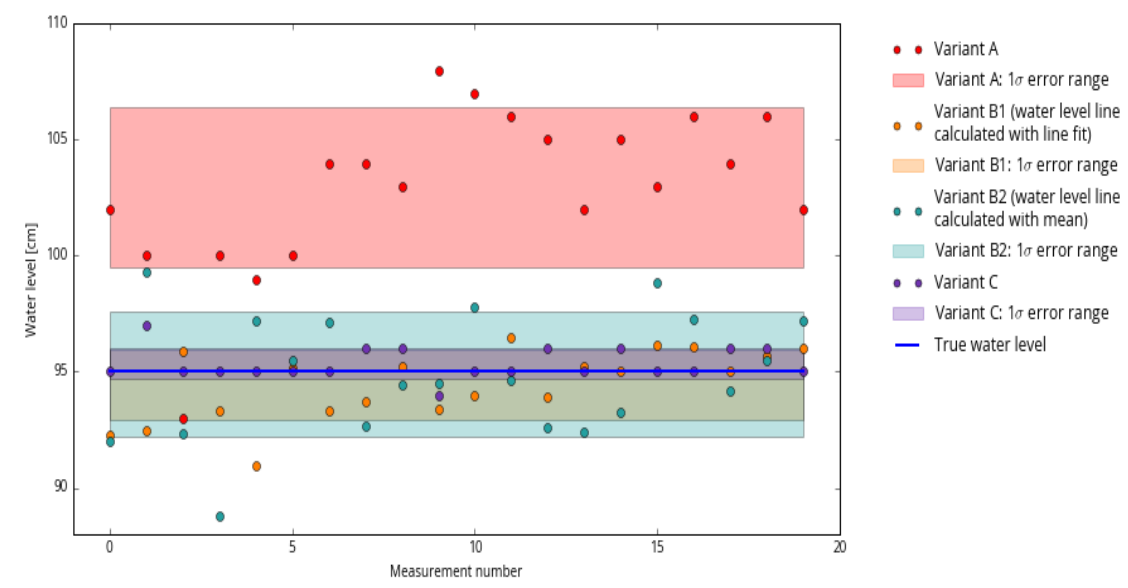

Fig. 5. Results of the different measurement methods

The data sets corresponding to the different measurement variants are shown in different colours. The individual data points are represented by the coloured dots and the $1 \sigma$ error range about the mean for each variant is shown by the filled areas. The results are also tabulated in Table 1. 


\begin{tabular}{|l|c|c|c|c|}
\hline Variant & $A$ & $B 1$ & $B 2$ & $C$ \\
\hline Mean [cm] & $102.95 \pm 3.44$ & $94.47 \pm 1.51$ & $94.88 \pm 2.69$ & $95.35 \pm 0.67$ \\
\hline
\end{tabular}

Table 1. Results of the different measurement methods

It can be seen that Variant A consistently overestimates the water level. This is the most inaccurate method, and with the largest errors, also the most imprecise. Variants B and $\mathrm{C}$ determine the water level relatively accurately and the mean values of the data sets agree with the true water level within the calculated errors. Variant $C$ achieves the highest precision of all the tested methods with a standard deviation of less than $1 \mathrm{~cm}$. This variant also allows the greatest flexibility as the measuring point is not fixed. However, the measurements take longer to perform than with variant A or B as all four correspondence points must be input manually by the user. Variants A and B may therefore be preferred if a quick measurement is important. It should be noted that the above results were achieved in an ideal environment. Under real conditions, appropriate reference objects may only be available with certain limitations (e.g., the plane in which a reference object lies may not be completely identical to the plane in the water line is measured), introducing larger inaccuracies.

\section{Conclusion and outlook}

In this article, methods for measuring the water level using the sensors integrated in smartphones (mobile sensing) have been presented. It has been described how mobile VGI data can be incorporated into a flood forecasting system to support flood management in small drainage basins. The use of such mobile techniques for measuring the water level or recording snow depth and precipitation intensity increases the density of available hydrological and meteorological data and can thus improve the accuracy of flood forecasts.

It has been shown that image-based measurement methods can be developed to determine the actual water level to within a few centimetres by using the built-in orientation and camera sensors in common mobile devices. The presented evaluation reveals that such high accuracies can be realised under ideal conditions. The challenging task will be to achieve equally satisfying results when transferring the presented measurement techniques into real-world environments. In real-world situations, further conditions and parameters have to be taken into account when performing measurements using the discussed techniques. An essential premise will be finding and surveying suitable measurement locations meeting the aforementioned requirements of the measurement methods (e.g., suitable reference objects, accessible fixed measurement positions, definable flow cross sections etc.). In addition, the identification and marking of such reference points and measurement positions as well as the usability and user friendliness of the mobile app will be an important role for the success of the mobile sensing methods. Only if the instructions and exact measurement procedures are clearly and 
unambiguously comprehensible to all user groups can the complex measurement methods be executed successfully.

In the next steps, the feasibility of the methods will therefore be tested more intensively under real-life conditions at selected locations along small rivers. Following this, a pilot phase involving a larger number of potential users will allow the evaluation of the proposed flood forecasting platform along with the general feasibility and efficiency of the VGI approach within the scope of flood management. Only after such field tests are complete, can the accuracy and efficiency of the presented water level measurement methods be evaluated conclusively.

\section{References}

1. Müller, U.: Hochwasserrisikomanagement - Theorie und Praxis. Vieweg+Teubner, Wiesbaden (2010)

2. Neumayer, E., Barthel, F.: Normalizing economic loss from natural disasters - A global analysis. Global Environmental Change 21, 13-24 (2011)

3. Kundzewicz, Z.W.: Floods - lessons about early warning systems. In: Late lessons from early warnings - science, precaution, innovation. European Environment Agency, EEA Report, No, 1/2013, pp. 347-368 (2013)

4. Blöschl, G.: Flood warning - on the value of local information. Int. J. River Basin Management 6(1), 41-50 (2008). doi:10.1080/15715124.2008.9635336

5. Fuchs-Kittowski, F.: Mobiles Crowdsourcing und Sensing. WISU 43(9), 1031-1038 (2014)

6. Goodchild, M. F.: Citizens as Voluntary Sensors - Spatial Data Infrastructure in the World of Web 2.0. Int. J. Spatial Data Infrastructures Research 2, 24-32 (2007)

7. Alcarria, R., Iturrioz, T.: Volunteered Geographic Information System Design - Project and Participation Guidelines. Int. J. Geo-Inf. 5(5) 108 (2016). doi:10.3390/ijgi5070108

8. See, L. et al.: Crowdsourcing, Citizen Science or Volunteered Geographic Information - The Current State of Crowdsourced Geographic Information. Int. J. Geo-Inf. 5(5) 55 (2016). doi:10.3390/ijgi5050055

9. Fuchs-Kittowski, F.; Bartusch, S.; Pfützner, B.; Fischer, F.: Mobile crowdsourcing of water level data. In: Wohlgemuth, V., Fuchs-Kittowski, F., Wittmann, J. (eds.): Int. Conf. environmental information and communication technologies (EnviroInfo2016). pp. 233-240. Shaker, Aachen (2016). ISBN 978-3-8440-4687-8

10. Neubauer, G., Nowak, A., Jager, B., Kloyber, C., Flachberger, C., Foitik, G., Schimak, G.: Crowdtasking - A New Concept for Volunteer Management in Disaster Relief. In: Hřebíček, J., Schimak, G., Kubásek, M., Rizzoli, A, (eds.): Environmental Software Systems - Fostering Information Sharing (ISESS2013), vol. 413, pp. 345-356. Springer, Berlin.

11. Middelhoff, M., Widera, A., van den Berg, R., Hellingrath, B., Auferbauer, D., Pielorz, J., Havlik, D.: Crowdsourcing and Crowdtasking in Crisis Management - Lessons Learned From a Field Experiment Simulating a Flooding in City of the Hague. In: International Conference on Information and Communication Technologies for Disaster Management (ICTDM'2016).

12. Sieber, R.: Public Participation Geographic Information Systems: A Literature Review and Framework. Annals of the Association of American Geographers 96, 491-507 (2006)

13. Burke, J., Estrin, D., Hansen, M., Ramanathan, N., Reddy, S., Srivastava, M. B.: Participatory sensing. Workshop on World-Sensor-Web (WSW’06): Mobile Device Centric Sensor Networks and Applications, pp. 117-134 (2006) 
14. Schimak, G., Havlik, H., Pielorz, J.: Crowdsourcing in Crisis and Disaster Management Challenges and Considerations. In: Denzer, R., Argent, R.M., Schimak, G., Hřebíček, J. (eds.): Int. Symp. Environmental Software Systems (ISESS 2015), vol. 448, pp. 56-70, Springer, Heidelberg (2015)

15. Abecker, A., Braun, S., Kazakos, W., Zacharias, V.: Participatory Sensing for Nature Conservation and Environment Protection. In: Arndt, H.-K., Knetsch, G., Pillmann, W. (eds.): EnviroInfo 2012, pp. 393-401. Shaker, Aachen (2012). ISBN: 978-3-8440-1248-4

16. Kaewkitipong, L., Chen, C., Ractham, P.: Lessons Learned from the Use of Social Media in Combating a Crisis - A case Study of 2011 Thailand Fodding Disaster. Int. Conf. on Information Systems (ICIS2012), pp. 1-17 (2012)

17. De Longueville, B., Annoni, A., Schade, S., Ostlaender, N., Whitmore, C.: Digital Earth’s Nervous System for crisis events - real-time Sensor Web Enablement of Volunteered Geographic Information. Int J. Digital Earth 3(3), 242-259 (2010) doi:10.1080/17538947.2010.484869

18. Poser, K., Dransch, D.: Volunteered geographic information for disaster management with application to rapid flood damage estimation. Geomatica 64, 89-98 (2010)

19. Goodchild, M.F., Glennon, J.A.: Crowdsourcing geographic information for disaster response - a research frontier. Int. J. Digital Earth, 3(3), 231-241 (2010) doi: 10.1080/17538941003759255

20. Yates, D., Paquette, S.: Emergency knowledge management and social media technologies - A case study of the 2010 Haitian earthquake. Int. J. Information Management 31, 6-13 (2011)

21. Huang, C.-M., Chan, E., Hyder, A.: Web 2.0 and Internet Social Networking: A New tool for Disaster Management? - Lessons from Taiwan. BMC Medical Informatics and Decision Making, 10(1), 57 (2010) doi:10.1186/1472-6947-10-57

22. Herschy, R. W.: Streamflow Measurement, CRC Press, Reading (UK), 3rd edition (2008)

23. Smith, L. C., Pavelsky, T. M.: Estimation of river discharge, propagation speed, and hydraulic geometry from space: Lena River, Siberia. Water Resources Research 44(3) (2008) doi:10.1029/2007WR006133

24. Iwahashi, M., Udomsiri, S., Imai, Y., Fukuma, S.: Water level detection for river surveillance utilizing JP2K wavelet transform. IEEE Asia-Pacific Conference on Circuits and Systems, Proceedings (APCCAS 2006), 1741-1744 (2006)

25. Kim, Y., Park, H., Lee, C., Kim, D., Seo, M.: Development of a Cloud-based Image Water Level Gauge Development of River Eye system. INPRA 2, 22-29 (2014)

26. Lo, S.W., Wu, J. H., Lin, F.P., Hsu, C.H.: Visual sensing for urban flood monitoring. Sensors 15(8), 20006-20029 (2015) doi:10.3390/s150820006

27. Royem, A.A., Mui, C.K., Fuka, D.R., Walter, M.T.: Technical Note: Proposing a low-tech, affordable, accurate stream stage monitoring system. Transactions of the ASABE 55, 22372242 (2012)

28. Lowry, C.S., Fienen, M.N.: CrowdHydrology: Crowdsourcing hydrologic data and engaging citizen scientists. GroundWater 51, 151-156 (2013)

29. KISTERS: Einfach smart - App für Pegelmessung auf Knopfdruck. https://www.kisters.de/fileadmin/user_upload/Wasser/Produkte/WISKI/Produktblaetter/MobileWaterTracker_de_mail.pdf

30. Amin, D., Govilkar, S.: Comparative Study of Augmented Reality SDK’S. Int. J. Computational Sciences \& Applications (IJCSA) 5(1), 11-26 (2015)

31. Fuchs-Kittowski, F., Simroth, S., Himberger, S., Fischer, F.: A content platform for smartphone-based mobile augmented reality. Int. Conf. Informatics for Environmental Protection (EnviroInfo2012) pp. 403-412. Shaker, Aachen (2012) 
32. Lanfranchi, V., Wrigley, S., Ireson, N., Wehn, U., Ciravegna, F.: Citizens' Observatories for Situation Awareness in Flooding. Int. Conf. Information Systems for Crisis Response and Management (ISCRAM 2014) pp.154-154 (2014)

33. WeSenseIt: Sensor Data - Sensors, Citizens, Information and Models. http://wesenseit.eu/wp-content/uploads/2014/12/data.pdf

34. Fuchs-Kittowski, F., Faust, D.: Architecture of Mobile Crowdsourcing Systems. In: Baloian, N., Burstein, F., Ogata, H., Santoro, F., Zurita, G. (eds.): Int. Conf. Collaboration and Technology (CRIWG2014) LNCS, vol. 8658, pp. 121-136. Springer, Heidelberg (2014). doi:10.1007/978-3-319-10166-8_12

35. Kwonkyu, Y., Byungman, Y., Seokmin, L.: Surface Image Velocity Measurement System for Wide Rivers Using Smartphones. IAHR World Congress, E-Proceedings, pp. 1-3 (2015) http://89.31.100.18/ iahrpapers/81007.pdf

36. Garg, K., Nayar, S. K.: Vision and rain. Int. J. Computer Vision 75(1), 3-27 (2007) doi: 10.1007/s11263-006-0028-6 